\title{
Regulation of gut glutamine metabolism: role of hormones and cytokines
}

\author{
BY NAJI N. ABUMRAD, SOOJIN KIM AND \\ PATRICIA E. MOLINA \\ Department of Surgery, State University of New York, Stony Brook, NY 11794-8191, USA
}

The use of glutamine by several types of rapidly-dividing cell such as enterocytes (Ashy \& Ardawi, 1988), fibroblasts, malignant cells and reticulocytes (Rapaport et al. 1970; Newsholme et al. 1985) is well established. This has formed the basis for using this amino acid as an adjuvant nutritional supplement. The early studies of Windmueller and colleagues (Windmueller \& Spaeth, 1974, 1975; Pinkus \& Windmueller, 1977; Windmeuller, 1982), and later studies by others (Ardawi \& Newsholme, 1985) have established the avidity of enterocytes and colonocytes to utilize glutamine as an energy source. Little is known, however, about the various alterations in glutamine metabolism that occur during periods of stress. The present paper attempts to address some of the variables involved in intestinal glutamine metabolism during periods of stress. We have chosen to address the effects of various hormones and cytokines on the inter-organ metabolism of this amino acid. The data presented here have, in a large part, been generated in the conscious dog model.

It is presently well established that nutrient supplementation with glutamine is likely to yield beneficial effects on the intestinal mucosa. The mechanism by which such beneficial effects are attained remains undetermined. Several recent studies have established that the administration of intraluminal glutamine can function as a local trophic factor (Souba et al. 1985). Several hypotheses have been suggested, but the one that has not been examined is the local effects of glutamine on the proliferative capacity of the intestinal mucosa. Recent observations (N. Yazigi, N. Okamura and N. N. Abumrad, unpublished results) from our laboratory indicate that the local intraluminal administration of this amino acid resulted in significant enhancement in the mitotic index of the distal ileal mucosa. These same effects were mimicked by intraluminal perfusion with a hypotonic solution (containing 90-115 mM-Na ${ }^{+}$), suggesting that this effect is due to a change in cell volume. A previous study which was only reported in an abstract form, has attributed this effect to the synthesis of intraluminal $\mathrm{NH}_{3}$, which as it diffuses into the interstitial space traps one proton which is then exchanged for the re-absorption of one $\mathrm{Na}^{+}$or one $\mathrm{K}^{+}$ion (Neptune \& Mitchell, 1964). This phenomenon is identical to the role that $\mathrm{NH}_{3}$ and $\mathrm{NH}_{4}{ }^{+}$play in regulating acid-base homeostasis across the renal tubules. Other potential beneficial effects, which are less specific to the intestinal mucosa, are related to the supply of precursors and nitrogenous endproducts which are used for the synthesis of purines and pyrimidines and for the synthesis of urea and other amino acids (Addae \& Lotspeich, 1968; Welbourne, 1987; Newsholme et al. 1988; Mommsen \& Walsh, 1989).

\section{FASTING}

Studies by Felig et al. (1973) in human volunteers and diabetic subjects fasted overnight reported a net splanchnic output of glutamine. Conversely, studies by Marliss et al. (1971) demonstrated net glutamine extraction across the splanchnic bed of normal 
human volunteers fasted overnight. The reason for these conflicting results may be attributed to the inability to measure portal-vein glutamine levels and, hence, the inability of the investigators to differentiate between substrate balances across the gut, liver, or other extrahepatic splanchnic tissues, such as the spleen, mesenteric fat or the pancreas.

Studies from our laboratory in the multiple-catheterized conscious dog established the capacity of the gut to extract glutamine from the blood at a rate comparable with that of the liver (Miller et al. 1983). In these studies we measured the arterial-portal venous differences of glutamine and we estimated blood flow across the portal-drained viscera either using the indocyanine green clearance method, or using doppler flow-meters (Williams et al. 1992). Further, these studies showed that progressive fasting (up to 4 d) was associated with enhanced utilization of glutamine by the gut. We also showed that fasting was associated with a switch from a predominant production of alanine by the gut to that of $\mathrm{NH}_{4}{ }^{+}$. These findings would suggest that overnight fasting is associated with a predominant dependence on transaminase enzymes by the intestinal mucosa, but as fasting progresses there is a change to dependence on the glutaminase enzymes, with enhanced production of $\mathrm{NH}_{4}{ }^{+}$. The mechanism for all these changes remains to be determined. The work from our laboratory, as well as from others (Welbourne, 1987), would suggest that the increased uptake of glutamine seen during fasting may be secondary to the prevailing mild but compensated metabolic acidosis associated with short-term fasting (Cersosimo et al. 1986). Other potential causes could include changes in the hormonal milieu, such as a decrease in plasma insulin and increases in plasma glucagon and corticosteroids that are seen with progressive fasting.

\section{Effect of exercise}

Most of the studies relating to the various metabolic changes that occur with exercise have focused their attention on the role of the liver and skeletal muscle. Little information is available, however, on the role of the intestines, and in particular on glutamine metabolism, during periods of acute exercise. Wasserman et al. $(1991 a, b)$ examined amino acid balances in a conscious dog model after an overnight fast, during a basal period and during $150 \mathrm{~min}$ of moderately-intense treadmill exercise (at $100 \mathrm{~m} / \mathrm{min}$, $12 \%$ gradient). These authors showed that exercise was associated with a $17 \%$ reduction in blood glutamine and an approximately $80 \%$ enhancement in glutamine extraction by the gut as shown in Fig. 1. This increase was associated also with increased percentage extraction (from approximately 8 during the basal period to approximately 16 after 60 min of exercise). These changes were associated with transient increases in net gut output of $\mathrm{NH}_{4}{ }^{+}$, with changes in net output of alanine. Plasma $\mathrm{NH}_{4}{ }^{+}$did not change, while plasma alanine levels decreased by $30 \%$. The changes in the gut handling of other amino acids were also interesting. The gut output of total $\alpha-\mathrm{NH}_{2}-\mathrm{N}$ (derived as the sum of all other amino acids released) during exercise exceeded that net uptake of glutamine by a ratio of $3: 1$. Thus, we suggest that the changes in intestinal glutamine metabolism are intimately tied to the needs of the liver for substrates, and in particular amino acids, to meet the increased demands for enhanced glucose utilization during exercise. Under such conditions, the demands for increased delivery of gluconeogenic amino acids is augmented, and in this respect, the gut acts as a reservoir and a major source of these amino acids. The exercise protocol used in this study elicited significant increases in 


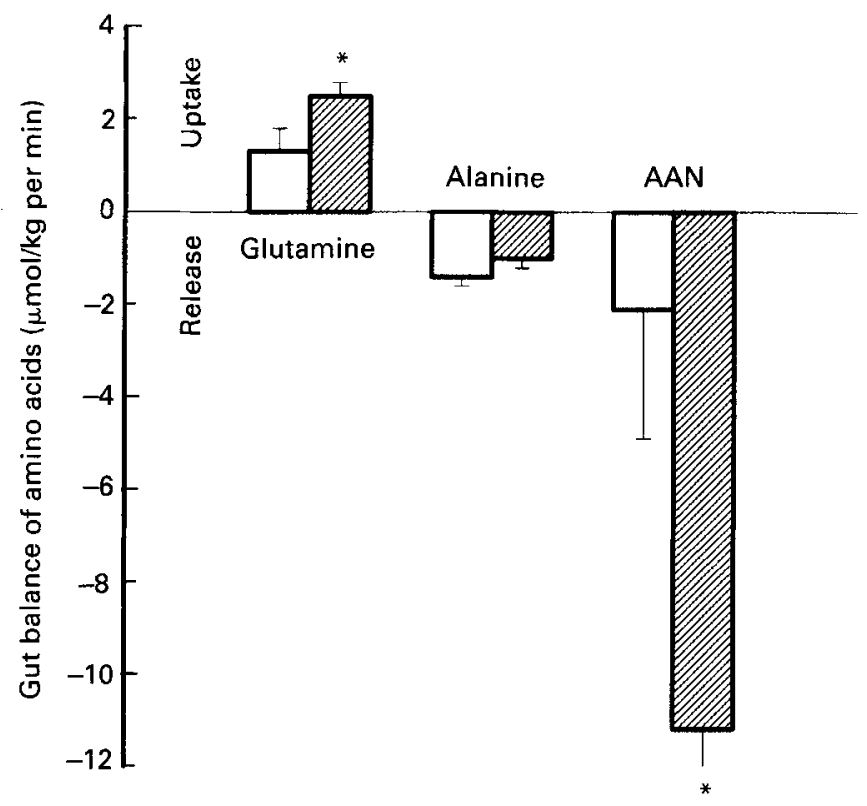

Fig. 1. Net glutamine uptake by the gut during a period of moderate-intensity exercise. The animals $(n 6)$ were previously fitted with catheters in the femoral artery and the portal vein. Following a 3-week recovery period, the animals were exercised on a treadmill at $100 \mathrm{~m} / \mathrm{min}$ (12\% gradient) for $150 \mathrm{~min}$. Net gut glutamine uptake was derived from the arterial-portal blood differences multiplied by the blood flow as determined by indocyanine green. $(\square)$, Basal, average values during a basal post-absorptive period; ( $\varangle$ ) exercise, the values averaged during the $45 \mathrm{~min}$ exercise period. AAN, amino acid-N. Values are means with their standard errors represented by vertical bars. Mean values were significantly different from basal value: $* P<0 \cdot 05$.

plasma glucagon, epinephrine, norepinephrine and a $50 \%$ reduction in circulating plasma insulin levels. Based on observations cited here, it is quite clear, however, that the changes in gut glutamine extraction can be attributed entirely to the increased plasma glucagon associated with exercise (Wasserman et al. 1989a,b).

\section{Effect of insulin}

The effect of physiological changes in plasma insulin on amino acids has not been addressed previously. As a result, we examined the effects of selective insulin withdrawal and selective hyperinsulinaemia (2-3-fold basal values) in a group of conscious dogs. These studies were accomplished by an intravenous infusion of cyclic somatostatin, to inhibit the secretion of insulin and glucagon, with simultaneous infusions of intraportal glucagon at a rate of $0.50-0.60 \mathrm{ng} / \mathrm{kg}$ per min intended to achieve arterial plasma glucagon levels at or near basal levels. In one set of animals intraportal insulin (at a rate of $600 \mu \mathrm{g} / \mathrm{kg}$ per $\mathrm{min}$ ) was co-infused to establish approximately 2-3-fold hyperinsulinaemia; euglycaemia was maintained by a variable infusion of glucose. In another set of animals intravenous somatostatin was administered in conjunction with intraportal glucagon (at the rate suggested previously), but with no insulin infusion. This rendered the animals with acute insulin deficiency. The findings (except those for glutamine) from both studies have been published already (Abumrad et al. 1982). Our studies showed 


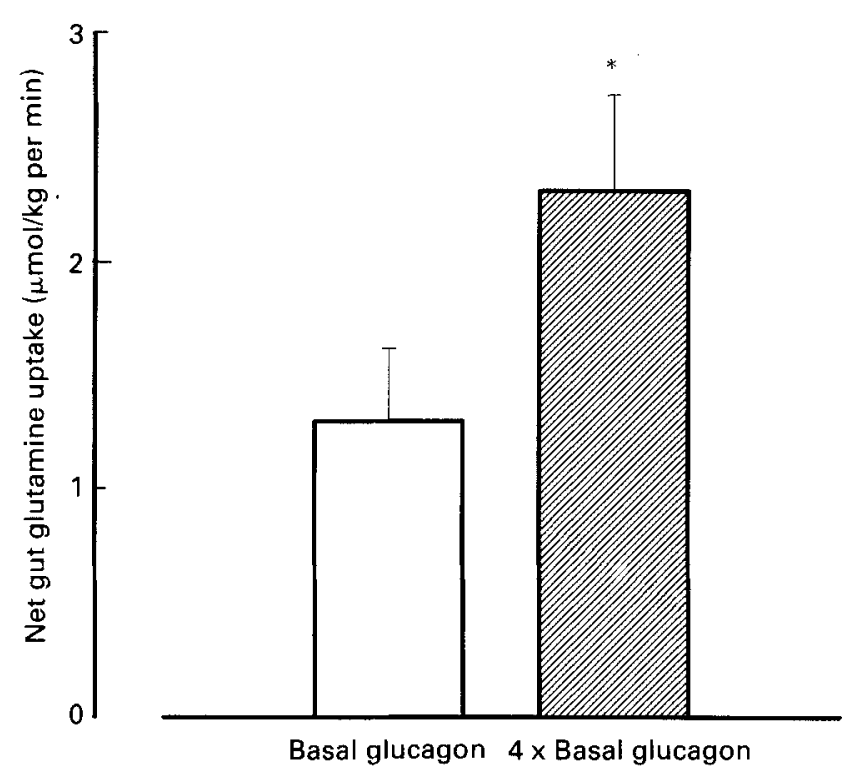

Fig. 2. Glutamine uptake by the gut during a basal post-absorptive period and following a $4 \mathrm{~h}$ intravenous infusion of somatostatin with simultaneous infusions of intraportal insulin ( $250 \mu \mathrm{U} / \mathrm{kg}$ per min) and glucagon (3.0 $\mathrm{ng} / \mathrm{kg}$ per $\mathrm{min})$. These rates were chosen to establish the arterial insulin levels near basal levels (approximately $15 \mu \mathrm{U} / \mathrm{ml}$ ) and the plasma glucagon levels to be 3-4-fold basal levels $(250-300 \mathrm{pg} / \mathrm{ml}$ ). Net gut glutamine uptake was determined during a $40 \mathrm{~min}$ basal period and during a $3 \mathrm{~h}$ hyperglucagonaemic period. The values represent the average of at least four to eight determinations during each period. Values are means with their standard errors represented by vertical bars. Mean value was significantly different from basal value: $* P<0.05$.

that neither acute insulin deficiency nor physiological hyperinsulinaemia was associated with any significant alterations in either plasma glutamine or changes in the rates of glutamine extraction by the gut. Hyperinsulinaemia was associated with significant decreases $(10-35 \%)$ in plasma amino acids, while selective insulin deficiency for $4 \mathrm{~h}$ was associated with significant increases in various plasma amino acids, in particular the branched-chain amino acids, leucine, isoleucine and valine. Taken together, these results indicate that physiological changes in plasma insulin are not likely to result in any significant alterations in intestinal glutamine metabolism.

\section{Effect of glucagon}

One of the hallmarks of the stress response is an increase in plasma glucagon. In order to address the role of physiological changes in plasma glucagon in relation to intestinal glutamine metabolism, we carried out a set of studies identical to those described previously. A group of conscious animals received an intravenous infusion of cyclic somatostatin with simultaneous infusion of intraportal insulin (to achieve basal levels) and glucagon (3.0-3.5 $\mathrm{ng} / \mathrm{kg}$ per min) intended to achieve 4-fold basal arterial glucagon levels (an increase to approximately $300 \mathrm{pg} / \mathrm{ml}$ ). Hyperglucagonaemia was associated with a $70 \%$ increase in glutamine extraction by the intestine (as shown in Fig. 2), with preponderance of $\mathrm{NH}_{4}{ }^{+}$release by the 'gut' over that of alanine. These studies suggested 
that glucagon was selectively stimulating glutaminase ( $E C$ 3.5.1.2) enzyme in the gastrointestinal mucosa (Geer et al. 1987). The mechanism of such a stimulation remains undetermined. Recent unpublished preliminary findings, also carried out using dogs fasted overnight and for $4 \mathrm{~d}$ (R. J. Geer and N. N. Abumrad, unpublished results) suggest that glucagon's stimulatory effect on intestinal glutamine metabolism is most probably mediated by increases in the $\mathrm{Na}^{+}-\mathrm{H}^{+}$transporter. The significance of these findings, however, remains to be determined.

\section{Effect of corticosteroids}

The role that corticosteroids play in modulating glutamine utilization by the gut has been the subject of several studies in our laboratory. Two such representative studies were carried out by McCallister et al. (1983) and by Miller et al. (1984). In these studies the animals were treated with dexamethasone $(1.0 \mathrm{mg} / \mathrm{d}$ for $2-4 \mathrm{~d})$. Glutamine balance across the portal-drained viscera was determined following an overnight fast. These studies showed that high dexamethasone treatment resulted in an approximately 2 -fold increase in glutamine uptake by the gut. Recent studies from our laboratory suggest that this effect might be related to changes in the intralumen $\mathrm{pH}$ of the intestinal mucosa, and that such changes are in many ways identical to those seen with fasting (N. Yazigi, N. Okamura and N. N. Abumrad, unpublished results). It remains to be determined, however, whether these effects are additive.

\section{Effect of hypoglycaemia}

Over the past few years, our laboratory has been studying metabolic responses to insulin-induced hypoglycaemia. Most of the studies were performed using the conscious dog model (Hourani et al. 1990a,b; Molina et al. 1993), with some studies carried out in the rat (Molina \& Abumrad, 1994b). Our findings were consistent with a significant enhancement in whole-body proteolysis during a hypoglycaemic episode. When studying the source of the amino acids released during a hypoglycaemic episode we were surprised to find that the gut was the major source of these substrates. Hypoglycaemia was associated with a significant release of all the investigated amino acids across the gastrointestinal tract, except for glutamine. The gut uptake of glutamine declined from an average of $1.6(\mathrm{SE} 0.3) \mu \mathrm{mol} / \mathrm{kg}$ per min to almost 0.1 (SE 0.2$) \mu \mathrm{mol} / \mathrm{kg}$ per min, as shown in Fig. 3. Here again, the mechanism of these changes remains elusive. It is of interest to note that hypoglycaemia is associated with significant increases in plasma glucagon, cortisol, epinephrine, norepinephrine, and $\beta$-endorphin. In an attempt to examine whether any of these hormones played a role in the pathogenesis of the enhanced intestinal (and whole-body) proteolytic responses, we infused these hormones, singly and in combination (N. Yazigi, N. Okamura and N. N. Abumrad, unpublished results), to simulate the prevailing plasma levels, and we failed to reproduce any of the protein catabolic responses associated with hypoglycaemia. As a result, we investigated the role that the central nervous system (CNS) played in modulating this response.

In subsequent studies, similar to those described previously, we placed catheters in the internal carotid and vertebral arteries of dogs. They were allowed to recover for a period of 3 weeks post-operatively, before studying them in the conscious state. The animals were then subjected to hypoglycaemia (plasma glucose levels 400 (sE 30) $\mathrm{mg} / \mathrm{l}$ ), with the 


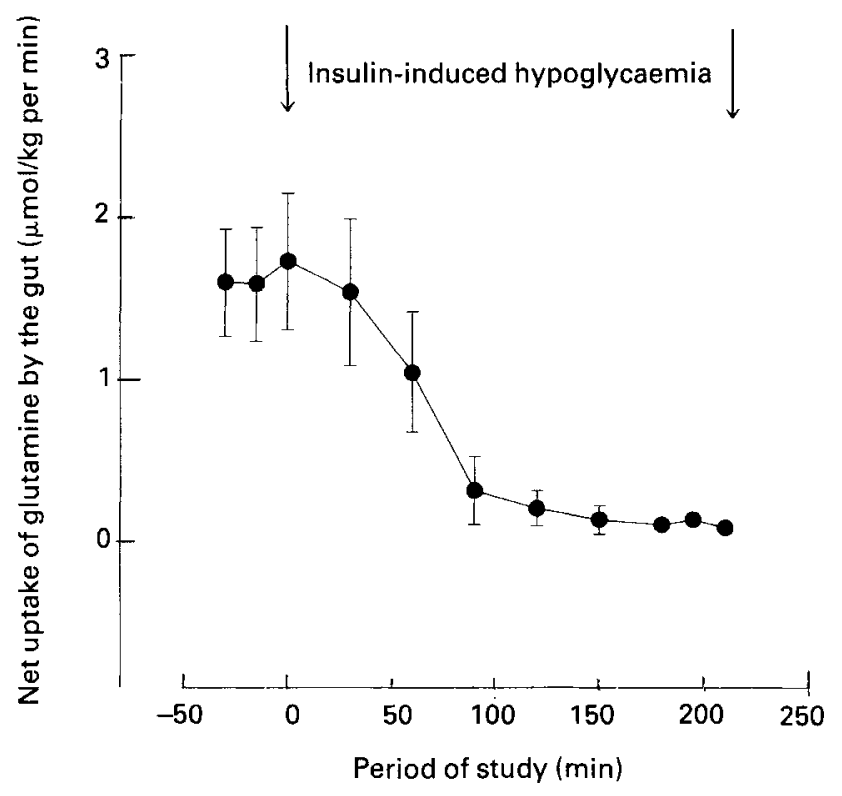

Fig. 3. Net gut glutamine uptake during a $4 \mathrm{~h}$ period of insulin-induced hypoglycaemia. Insulin was infused intravenously at $5.0 \mathrm{mU} / \mathrm{kg}$ per min beginning at time 0 and the infusion lasted for $4 \mathrm{~h}$. Plasma glucose was allowed to drop to 400 (SE 30) $\mathrm{mg} / \mathrm{l}$. Net gut glutamine uptake was determined during a $40 \mathrm{~min}$ basal period and during a $4 \mathrm{~h}$ hypoglycaemic period. The values represent the average of at least four to eight determinations during each period. Values are means with their standard errors represented by vertical bars.

exogenous infusion of insulin. One group was simultaneously given enough glucose through both carotid and vertebral arteries to maintain approximate CNS-euglycaemia (i.e. the CNS glucose levels were approximately basal, but the rest of the body was subjected to hypoglycaemia). The other group of animals, received saline $(9 \mathrm{~g} \mathrm{NaCl} / \mathrm{l})$ instead, thus rendering the animals totally hypoglycaemic (i.e. CNS + rest of the body). Our findings indicate that the group that was allowed to maintain CNS glucopenia showed the same enhanced proteolysis seen in the previous studies, with the gut responsible for most of the increased proteolytic response mentioned previously. However, the group of animals that had the CNS protected against hypoglycaemia failed to show any increased proteolytic response by the body and, most importantly, the gut did not increase its output of amino acids, even though the general arterial circulation (except for the brain) was subjected to hypoglycaemia. These findings indicated conclusively that the CNS was the primary triggering organ responsible for the enhanced proteolysis by the body and by the gut during a period of hypoglycaemia. Presently our laboratory is actively pursuing the various potential mediators involved in this CNSelicited response.

\section{Role of cytokines}

Several studies have suggested that sepsis is associated with decreased uptake of glutamine by the gut and with decreased transport of glutamine across the brush-border 


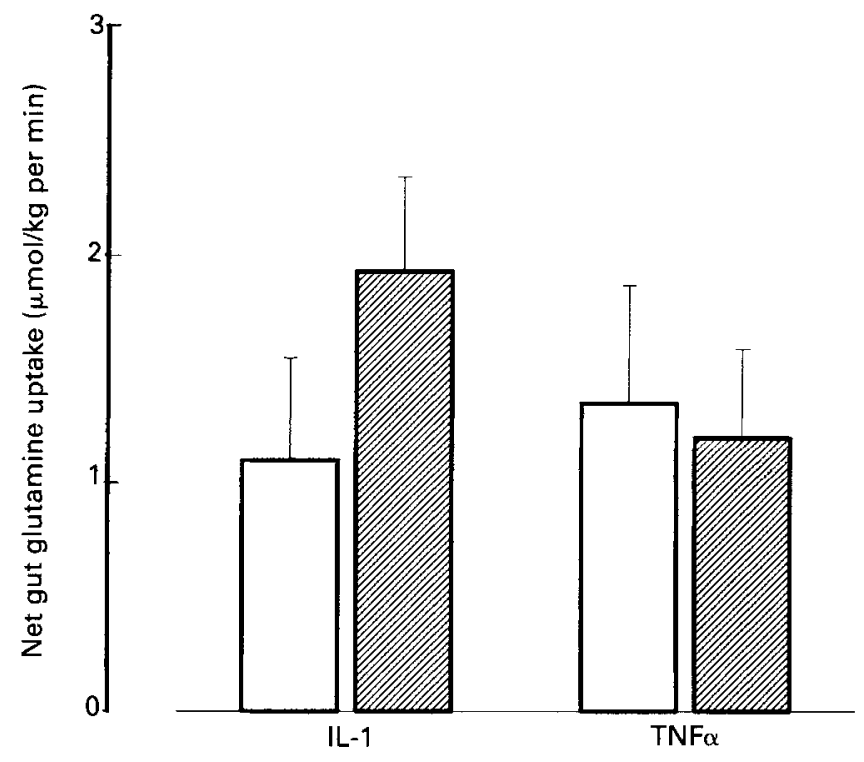

Fig. 4. Glutamine uptake by the gut during a $2 \mathrm{~h}$ infusion (因) of either interleukin-1 (IL-1) or tumour necrosis factor $\alpha(\mathrm{TNF} \alpha) .(\square)$, Control. The data were modified from Fukushima et al. (1992). Values are means with their standard errors represented by vertical bars. Mean value was significantly different from control value: $* P<0 \cdot 05$.

membranes (Souba et al. 1985). It has been suggested that most, if not all, these responses are mediated by the cytokines released during a septic episode. Most notable among these are interleukin-1 (IL-1) and tumour necrosis factor $\alpha$ (TNF $\alpha$ ). Fukushima et al. (1992), examined the effects of IL-1 and TNF $\alpha$ on various haemodynamic variables and inter-organ fluxes of amino acids. IL-1 infusion resulted in a hyperdynamic state, with no significant alterations in the gut balances of amino acids. IL-1 infusion, however, resulted in significant elevations (3-4-fold) in gut glutamine uptake, as shown in Fig. 4. On the other hand, TNF $\alpha$ infusion did not cause a hyperdynamic state, and it did not alter the uptake of amino acids, including glutamine. These findings showed that these cytokines had differential effects on the uptake of glutamine by the gut.

In conclusion, it appears that the gut handling of glutamine is highly dependent on the prevailing hormonal and cytokine conditions. There is also some evidence to suggest that the gut utilization of glutamine, and other amino acids, may be highly dependent also on the signals received from the CNS. In the case of hypoglycaemia we presented convincing data to suggest that all the signals for enhanced proteolysis, and especially the output of amino acids by the gut, during a period of hypoglycaemia are all neural in origin (Molina \& Abumrad, 1994a). These are not mediated by the classic hormonal changes, i.e. changes in the circulating levels of insulin, glucagon, cortisol and catecholamines. Thus, more work is required to address the various factors that influence the gut handling of glutamine and other amino acids in vivo. 


\section{REFERENCES}

Abumrad, N. N., Jefferson, L. S., Rannels, S. R., Williams, P. E., Cherrington, A. D. \& Lacy, W. W. (1982). Role of insulin in the regulation of leucine kinetics in the conscious dog. Journal of Clinical Investigation 70, 1031-1041.

Addae, S. K. \& Lotspeich, W. D. (1968). Relation between glutamine utilization and production in metabolic acidosis. American Journal of Physiology 215, 269-277.

Ardawi, M. S. M. \& Newsholme, E. A. (1985). Fuel utilization in colonocytes of the rat. Biochemical Journal 231, 713-719.

Ashy, A. A. \& Ardawi, M. S. M. (1988). Glucose, glutamine and ketone body metabolism in human enterocytes. Metabolism 37, 602-609.

Cersosimo, E., Williams, P. E., Radosevich, P. M., Hoxworth, B. T., Lacy, W. W. \& Abumrad, N. N. (1986). Role of glutamine in adaptations in nitrogen metabolism during fasting. American Journal of Physiology 250, E622-E628.

Felig, P., Wahren, J., Karl, I., Cerasi, F., Luft, R. \& Kipnis, D. M. (1973). Glutamine and glutamate metabolism in normal and diabetic subjects. Diabetes 22, 573-576.

Fukushima, R., Saito, I. I., Taniwaka, K., Hiramatu, T., Morioka, Y. \& Abumrad, N. N. (1992). Different roles of IL- 1 and TNF on hemodynamics and inter-organ amino acids metabolism in awake dogs. American Journal of Physiology 262, E275-E281.

Geer, R. J., Williams, P. E., Lairmore, T. \& Abumrad, N. N. (1987). Glucagon: An important stimulator of gut and hepatic glutamine metabolism. Surgical Forum 38, 27-29.

Hourani, H., Lacy, D. B., Nammour, T. M., Abumrad, N. N. \& Morris, J. A. (1990). Differential effects of alpha and beta adrenergic blockade on glucose and lactate metabolism during acute stress. Journal of Trauma 30, 1116-1124.

Hourani, H., Williams, P. E., Morris, J, A., May, M. E. \& Abumrad, N. N. (1990). Effect of insulin-induced hypoglycemia on protein metabolism in vivo. American Journal of Physiology 259, E342-E350.

McCallister, B., Miller, B. M., Lacy, W. W., McRae, J. \& Abumrad, N. N. (1983). The effect of acute and chronic glucocorticoid excess on leucine kinetics and on protein turnover in vivo. Journal of Surgical Research 35, 426-432.

Marliss, E., Aoki, T. T., Pozefsky, T., Most, A. S. \& Cahill, G. F. Jr (1971). Muscle and splanchnic glutamine and glutamate metabolism in post-absorptive and starved man. Journal of Clinical Investigation 50, 814-817.

Miller, B. M., Cersosimo, E., McRae, J., Williams, P. E., Lacy, W. W. \& Abumrad, N. N. (1983). Inter-organ relationships of alanine and glutamine during fasting in the conscious dog. Journal of Surgical Research $\mathbf{3 5}$, $310-318$

Miller, B., Hoxworth, B., Buckspan, R., Nanney, L., Lacy, W. W. \& Abumrad, N. N. (1984). Leupeptin's effect on organ weight, RNA, DNA, and protein content after long bone fracture in the rat. Journal of Surgical Research 36, 453-461.

Molina, P. E. \& Abumrad, N. N. (1994a). Gut-derived proteolysis during insulin-induced hypoglycemia: the pain that breaks down the gut. Journal of Parenteral and Enteral Nutrition 18, 549-556.

Molina, P. E. \& Abumrad, N. N. (1994b). Hypothalamus, glucopenia and fuel mobilization. In Organ Metabolism and Nutrition: Ideas for Future Critical Care, pp. 69-90 [J. M. Kinney and H. N. Tucker, editors]. New York: Raven Press.

Molina, P. E., El Tayeb, H., Hourani, H., Okamura, K., Nanney, L. B., Williams, P. \& Abumrad, N. N. (1993). Hormonal and metabolic effects of neuroglucopenia. Brain Research 614, 99-108.

Mommsen, T. P. \& Walsh, P. J. (1989). Evolution of urea synthesis in vertebrates. The piscine connection. Science 243, 72-75.

Neptune, E. M. \& Mitchell, T. G. (1964). Sodium and water transport by the everted rabbit intestinal sac. Federation Proceedings 23, 152 Abstr.

Newsholme, E. A., Crabtree, B. \& Ardawi, M. S. M. (1985). The role of high rates of glycolysis and glutamine utilization in rapidly dividing cells. Bioscience Reports 5, 393-400.

Newsholme, E. A., Newsholme, P., Curi, R., Challoner, E. \& Ardawi, M. S. M. (1988). A role for muscle in the immune system and its importance in surgery, trauma, sepsis and burns. Nutrition 4, 261-268.

Pinkus, L. M. \& Windmueller, H. G. (1977). Phosphate-dependent glutaminase of small intestine: localization and role in intestinal glutamine metabolism. Archives of Biochemistry and Biophysics 182, 506-517.

Rapaport, S., Rost, J. \& Shultz, M. (1970). On the metabolic regulation of glycolysis in erythrocytes. Bulletin of the Society of Clinical Biology 52, 1169-1186. 
Souba, W., Smith, R. J. \& Wilmore, D. W. (1985). Glutamine metabolism by the intestinal tract. Journal of Parenteral and Enteral Nutrition 9, 608-617.

Wasserman, D. H., Geer, R. J., Rice, D. E., Tracy, D., Flakoll, P. J., Brown, L. L., Hill, J. O. \& Abumrad, N. N. (1991). Interaction of exercise and insulin action in man. American Journal of Physiology 260, E37-E45.

Wasserman, D. H., Geer, R. J., Williams, P. E., Becker, T., Lacy, D. B. \& Abumrad, N. N. (1991). Interaction of gut and liver in nitrogen metabolism during exercise. Metabolism 40, 307-314.

Wasserman, D. H., Lacy, D. B., Goldstein, R. E. \& Cherrington, A. D. (1989). Exercise-induced fall in insulin and hepatic carbohydrate metabolism during exercise. American Journal of Physiology 256, E500-E508.

Wasserman, D. H., Spalding, J. S., Lacy, D. B., Colburn, C. A., Goldstein, R. E. \& Cherrington, A. D. (1989). Glucagon is a primary controller of the increments in hepatic glycogenolysis and gluconeogenesis during muscular work. American Journal of Physiology 257, E108-E117.

Welbourne, T. C. (1987). Inter-organ glutamine flow in metabolic acidosis. American Journal of Physiology 253, F1069-F1076.

Williams, P. E., Flakoll, P. J., Prexes-Steed, M. \& Abumrad, N. N. (1992). Surgical models to measure organ amino acid metabolism. In Modern Methods in Protein Nutrition and Metabolism, pp. 167-194 [S. Nissen, editor]. San Diego, CA: Academic Press.

Windmueller, H. G. (1982). Glutamine utilization by the small intestine. Advances in Enzymology 53, 201-215.

Windmueller, H. G. \& Spaeth, A. E. (1974). Uptake and metabolism of plasma glutamine by the small intestine. Journal of Biological Chemistry 249, 5070-5079.

Windmueller, H. G. \& Spaeth, A. E. (1975). Intestinal metabolism of glutamine and glutamate from the lumen as compared to glutamine from blood. Archives of Biochemistry and Biophysics 171, 662-672. 